\title{
TRIGO: TOLERÂNCIA AO ALUMÍNIO EM SOLUÇÃO NUTRITIVA (')
}

\author{
CARLOS EDUARDO DE OLIVEIRA CAMARGO $(2,3)$, JOĀO CARLOS FELICIO $(2,3)$ \\ L LAÉRCIO SOARES ROCHA JÚNIOR $\left.{ }^{2}\right)$
}

\begin{abstract}
RESUMO
Foi estudado o comportamento diferencial de 21 cultivares de trigo em soluções nutritivas, com arejamento, contendo seis concentrações de $\mathrm{A}^{3+}(0,2,4,6,8$ e $10 \mathrm{mg} / \mathrm{litro})$, à temperatura constante de $25 \pm 1^{\circ} \mathrm{C}$, e $\mathrm{pH} 4,0$. A tolerância foi medida pela capacidade de as raízes primárias continuarem a crescer em soluçāo sem aluminio, após 48 horas em solução contendo uma concentração conhecida de alumínio. Os cultivares $\mathrm{BH}-1146$, IAC-18, IAC-28, IAC-5, IAC-74, IAC-13, PAT-72247, IAC-22, BR-2, IAC-21 e IAC-24 foram considerados como tolerantes por exibir crescimento da raiz primária central após tratamento em solução contendo $10 \mathrm{mg} /$ /itro de $\mathrm{Al} \mathrm{l}^{3+}$; os cultivares IAC-17, IAC-161, Mitacoré e CEP-7780 mostraram reação de média tolerância ao $\mathrm{Al}^{3+}$, por apresentar crescimento da raiz primária central após tratamento em soluçōes contendo $6 \mathrm{mg} /$ litro de $\mathrm{Al}^{3++}$; os cultivares CNT-8, Alondra S-46, IAC-162, Paraguay-281 e IAC-23 foram considerados sensiveis ao $\mathrm{Al}^{3+}$, por mostrar crescimento das raízes primárias após tratamento em soluçōes contendo $2 \mathrm{mg} /$ litro de $\mathrm{Al}^{3+}$, e o 'Anahuac' demonstrou-se muito sensível ao $\mathrm{Al}^{3+}$, não exibindo crescimento das raízes primárias após tratamento em soluções contendo $2 \mathrm{mg} /$ litro de $\mathrm{Al}^{3+}$.
\end{abstract}

Termos de indexação: trigo, cultivares tolerantes e sensiveis, crescimento das raízes, soluçổes nutritivas, alumínio, toxicidade.

(1) Com recursos complementares do Acordo do Trigo entre as Cooperativas de Produtores Rurais do Vale do Paranapanema e a Secretaria da Agricultura do Estado de São Paulo, por meio do Instituto Agronômico. Trabalho apresentado na XIV Reuniáo Nacional de Pesquisa de Trigo, Londrina (PR), julho de 1986. Recebido para publicação em 20 de agosto de 1986. nas (SP).

(2) Seção de Arroz e Cereais de inverno, Instituto Agronómico (IAC), Caixa Postal 28, 13001 Campi-

(3) Com bolsa de suplementação do CNPq. 


\section{INTRODUÇÃO}

Grandes áreas dos solos brasileiros são ácidas. Tais solos contêm alumínio solúvel ou trocável que inibem o crescimento das raízes da maioria das variedades de trigo, resultando em reduzido perfilhamento das plantas e baixa produtividade.

O uso de soluções nutritivas contendo aluminio foi preconizado por MOORE et al. (1976) para diferenciar cultivares de trigo quanto à tolerância a esse elemento, uma vez que os solos ácidos, além do alumínio, podem apresentar teores tóxicos de ferro e manganês.

O trigo é uma espécie bastante sensivel ao $\mathrm{Al}^{3+}$, porém CAMARGO \& OLIVEIRA (1981), estudando dez cultivares em soluções nutritivas mostraram que 'Siete Cerros' e. 'Tobari-66' foram sensiveis a 1 e 3 mg/litro de Al ${ }^{3+;}$; 'Alondra-S-46', 'Alondra-S-45' e 'IAC-17', sensiveis a 6 mg/litro de $\mathrm{Al}^{3+}$, e 'BH-1146', 'IAC-5', 'IAC-18' e 'Londrina', tolerantes a $10 \mathrm{mg} / \mathrm{itro}$ de $\mathrm{A}^{3+}$. Esses resultados foram confirmados também na presença de solo ácido contendo $\mathrm{Al}^{3+}$. CAMARGO \& FELí$\mathrm{CIO}$ (1984) verificaram que os cultivares de centeio Branco e Goyarowo apresentaram-se tolerantes a $20 \mathrm{mg} / \mathrm{litro}$ de $\mathrm{Al}^{3+}$, enquanto diferentes cultivares de trigo e triticale mostraram-se sensiveis a $10 \mathrm{mg} /$ litro de $\mathrm{Al}^{3+}$ na soluçāo nutritiva. CAMARGO et al. (1984) observaram que os cultivares de arroz IAC-435, IAC-120, IAC-164, IAC-165, Pérola, Blue Bonnet, IAC-47 e IAC-25 mostraram-se tolerantes à presença de $20 \mathrm{mg} /$ /litro de $\mathrm{Al}^{3+}$ nas soluções. Dai concluir-se que arroz e centeio são mais tolerantes do que trigo em relação à toxicidade ao $\mathrm{Al}^{3+}$.

CAMARGO (1981) demonstrou que a tolerância do trigo 'BH-1146' é devida a um par de genes dominantes em cruzamentos desse cultivar com os cultivares sensiveis Tordo e Siete Cerros. Posteriormente, LAGOS et al. (1984), estudando plantas monossômicas $(2 n=41)$ de linhas aneuplóides e normais $(2 n=42)$ do genótipo Chinese Spring, identificadas citologicamente, as quais foram cruzadas com o ' $\mathrm{BH}-1146$ ', concluiram que o gene de tolerância ao $\mathrm{Al}^{3+}$ nesse cultivar está localizado no cromossomo 4D.

Uma das principais metas do programa de melhoramento genético do trigo no instituto Agronômico é a seleção de novos cultivares de porte baixo, porém com tolerância à toxicidade de alumínio, a partir de cruzamentos entre cultivares brasileiros (altos e tolerantes) e mexicanos (baixos, sensiveis ao $\mathrm{Al}^{3+} \mathrm{e}$ com alto potencial produtivo).

O presente trabalho teve por objetivo identificar os cultivares tolerantes ao $\mathrm{Al}^{3+}$ para cultivo em solos ácidos e/ou as melhores fontes de tolerância para usar no programa de melhoramento genético. 


\section{MATERIAL E MÉTODOS}

Os cultivares de trigo estudados foram divididos em dois grupos, a saber: (a) porte alto: BH-1146, CNT-8, IAC-18, IAC-28, IAC-5, IAC-74, IAC-13, IAC17, PAT-72247, IAC-22, Mitacoré, IAC-23, IAC-21, BR-2, CEP-7780, e (b) porte baixo: Alondra-S-46, IAC-162, IAC-161, Anahuac, Paraguay-281 e IAC-24.

As plântulas dos 21 cultivares foram testadas em soluçōes nutritivas de tratamento contendo $0,2,4,6,8$ e $10 \mathrm{mg} / \mathrm{litro}$ de $\mathrm{Al}^{3+}$, conforme método de $\mathrm{CA}$ MARGO \& OLIVEIRA (1981).

O delineamento estatístico foi o de blocos ao acaso com parcelas subdivididas: as parcelas eram compostas por seis concentrações de aluminio e, as subparcelas, pelos cultivares de trigo, efetuando-se duas repetições para cada uma das soluções de tratamento.

Os dados de crescimento das raizes foram analisados estatisticamente, considerando-se a média das vinte plântulas de cada cultivar após a influência prejudicial do aluminio nas diferentes soluções. A comparação entre as médias de crescimento da raiz dos 21 cultivares, dentro de uma mesma concentração de alumínio, e a comparação entre as médias de crescimento da raiz de um mesmo cultivar, em diferentes concentraçōes de aluminio, foram feitas pelo teste de Tukey.

\section{RESULTADOS E DISCUSSÃO}

Os resultados da análise estatística (Quadro 1) mostraram, pelo teste $F$, efeitos altamente significativos de concentrações de $\mathrm{Al}^{3+}$, cultivares e interações cultivares $x$ concentrações de $\mathrm{Al}^{3+}$.

O comprimento médio das raizes dos 21 cultivares de trigo, medido após 72 horas de crescimento nas soluções nutritivas completas depois de 48 horas de crescimento nas soluções de tratamento contendo seis diferentes concentrações de alumínio $(0,2,4,6,8$ e $10 \mathrm{mg} /$ /itro) encontram-se no quadro 2 .

Considerando-se as médias dos diferentes cultivares estudados em soluções de tratamento com ausência de $\mathrm{Al}^{3+}$, verifica-se que o ' $\mathrm{BH}-1146$ ' mostrou as raízes mais compridas, diferindo, pelo teste de Tukey ao nivel de $5 \%$, dos demais cultivares, à exceção do 'IAC-18', 'IAC-74' e 'PAT-72247'. Essas observações confirmam resultados de CAMARGO \& OLIVEIRA (1981), e CAMARGO \& FREITAS (1985): em uma solução com niveis adequados de nutrientes, na ausência de alumínio, com $\mathrm{pH} 4,0, \mathrm{O}$ 'BH-1146' apresentou o seu potencial genético no crescimento rápido das raizes, condição essa específica de cada genótipo.

Nas soluções de tratamento contendo $\mathrm{Al}^{3+}$, todos os cultivares reduziram o crescimento radicular em relação ao das soluções de tratamento contendo $0 \mathrm{mg} / \mathrm{litro}$ de $\mathrm{Al}^{3+}$. O 'Anahuac' revelou-se sensivel ao Al3+ (Figura 1), uma vez que suas raízes primárias não continuaram a crescer em solução sem alumínio, após um período de 48 horas em solução de tratamento contendo $2 \mathrm{mg} / \mathrm{litro}$ de $\mathrm{Al}^{3+}$. 
QUADRO 1. Análise da variância para crescimento da raiz de 21 cultivares de trigo estudados em soluçōes nutritivas de tratamento contendo seis diferentes concentraçōes de alumínio

\begin{tabular}{lrc}
\hline \multicolumn{1}{c}{ Causas de variação } & G.L. & Q.M. \\
\hline Repetições & 1 & 435,82 \\
Concentrações de Al ${ }^{3+}$ & 5 & $20946,69^{* *}$ \\
Erro I & 5 & 778,11 \\
Cultivares & 20 & $1293,27^{* *}$ \\
Cultivares x concentrações de $\mathrm{Al}^{3+}$ & 100 & $109,29^{* *}$ \\
Erro ll & 120 & 22,94 \\
\hline Total & 251 & \\
\hline
\end{tabular}

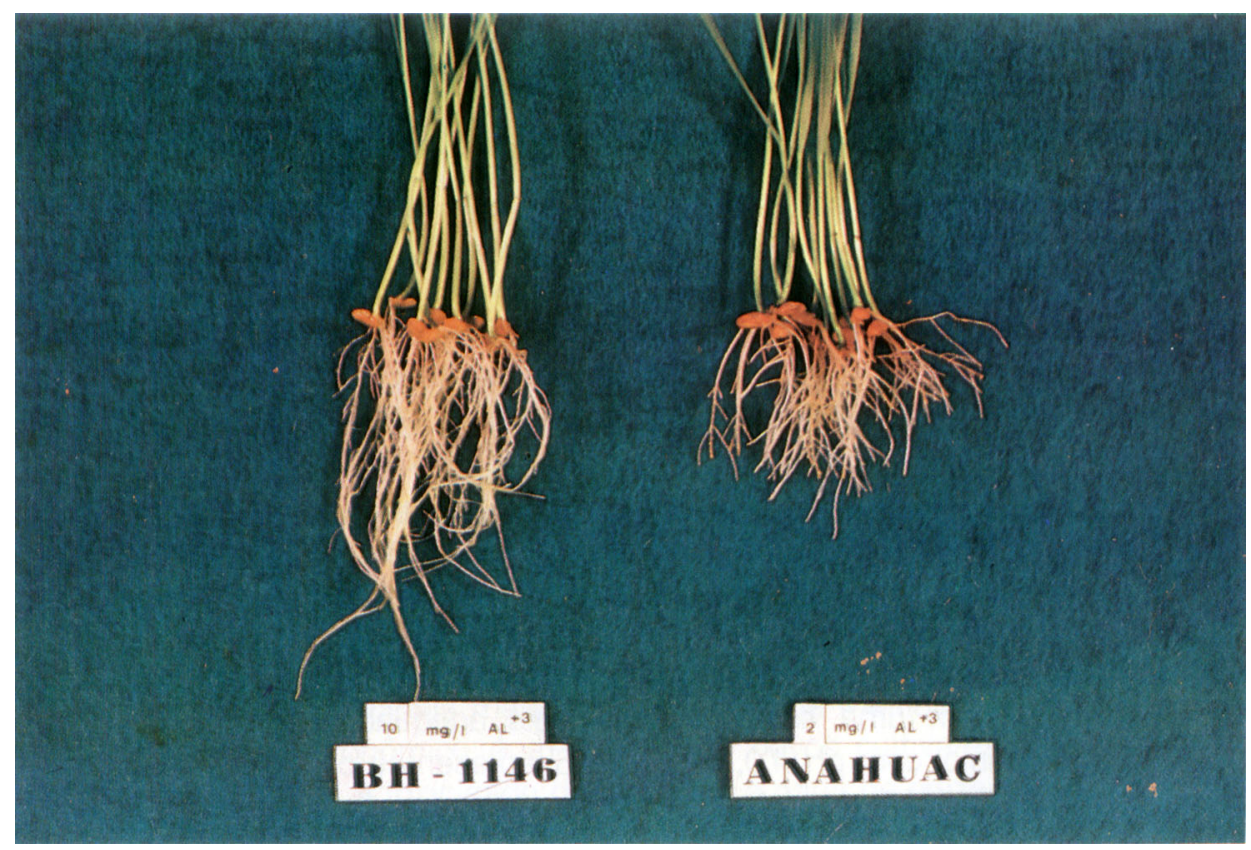

FIGURA 1. Sistemas radiculares dos cultivares de trigo $\mathrm{BH}-1146$ e Anahuac após 72 horas de crescimento nas soluçōes nutritivas completas, seguido a crescimento de 48 horas respectivamente, em soluçōes de tratamento contendo 10 e $2 \mathrm{mg} / \mathrm{ititro}$ de $\mathrm{Al}^{3+}$. 
QUADRO 2. Comprimento médio das raízes de 21 cultivares de trigo,medido após 72 horas de crescimento nas soluçōes nutritivas completas, seguido a crescimento de 48 horas nas soluções de tratamento contendo seis diferentes concentrações de alumínio

\begin{tabular}{|c|c|c|c|c|c|c|}
\hline \multirow{2}{*}{ Cultivares } & \multicolumn{6}{|c|}{ Concentrações de aluminio nas soluções de tratamento (mg/litro) } \\
\hline & 0 & 2 & 4 & 6 & 8 & 10 \\
\hline $\mathrm{BH}-1146$ & $95,1 \mathrm{a}$ & $62,6 a$ & $48,0 \mathrm{a}$ & $40,3 a$ & $32,6 a$ & $26,6 \mathrm{a}$ \\
\hline IAC-18 & $84,0 \mathrm{ab}$ & $57,3 a b$ & $44,1 a b$ & $36,6 a b$ & $21,5 \mathrm{ab}$ & $16,9 a b$ \\
\hline IAC-28 & $69,1 \mathrm{bcd}$ & $39,2 a b c d e f$ & $36,4 a b c d$ & $31,3 a b c$ & $23,1 a b$ & $16,6 a b$ \\
\hline IAC-13 & 58,9 bcde & $37,5 a b c d e f$ & $26,5 a b c d e$ & 12,0 bcde & $3,6 b$ & $6,7 a b$ \\
\hline PAT-72247 & $75,2 a b c d$ & 44,1 abcdef & 27, tabcde & $26,4 a b c d$ & $9,1 a b$ & $4,2 a b$ \\
\hline IAC-21 & $42,6 \mathrm{e}$ & 24,9 defgh & $27,4 a b c d e$ & $19,2 \mathrm{abcde}$ & $9,9 a b$ & $3,8 a b$ \\
\hline IAC-24 & $50,8 \mathrm{de}$ & 34,4 bcdefg & $34,5 a b c d$ & 29,2abcd & $14,1 \mathrm{ab}$ & $3,7 a b$ \\
\hline IAC-74 & $82,4 a b c$ & $56,4 a b c$ & $40,3 a b c$ & $27,6 a b c d$ & $4,3 b$ & $3,6 a b$ \\
\hline IAC-22 & $54,2 \mathrm{de}$ & 29,5defg & $23,9 a b c d e f$ & $12,8 \mathrm{bcde}$ & $2,3 b$ & $2,9 a b$ \\
\hline $\mathrm{IAC}-5$ & $52,2 \mathrm{de}$ & 30,8 defg & 22,5 bcdef & $23,0 a b c d e$ & $6,5 b$ & $2,5 a b$ \\
\hline BR-2 & $60,6 b c d e$ & $33,7 \mathrm{bcdefg}$ & $29,2 a b c d e$ & $12,3 \mathrm{bcde}$ & $3,5 b$ & 2,5ab \\
\hline IAC-17 & $66,5 \mathrm{bcde}$ & $46,2 a b c d e$ & 29,1 abcde & $11,5 \mathrm{bcde}$ & $0,0 b$ & $0,0 \mathrm{~b}$ \\
\hline IAC-161 & 63,4 bcde & 41,0abcdef & $18,7 \mathrm{cdef}$ & 9,5 cde & $0,0 b$ & $0,0 b$ \\
\hline Mitacoré & 64,1 bcde & $35,6 \mathrm{bcdefg}$ & $25,0 a b c d e f$ & 7,2 cde & $0,2 \mathrm{~b}$ & $0,0 b$ \\
\hline CEP-7780 & 68,4 bcde & $46,7 a b c d$ & 14,0 def & $4,5 \mathrm{de}$ & $0,0 b$ & $0,0 b$ \\
\hline IAC-23 & $56,9 \mathrm{de}$ & 26,6 defg & $12,8 \mathrm{def}$ & $0,0 \mathrm{e}$ & $0,0 \mathrm{~b}$ & $0,0 b$ \\
\hline IAC-162 & 65,5 bcde & $31,3 c$ defg & $4,7 \mathrm{ef}$ & $0,0 \mathrm{e}$ & $0,0 b$ & $0,0 b$ \\
\hline Alondra-S-46 & $50,7 \mathrm{de}$ & 21, oefgh & $0,0 f$ & $0,0 \mathrm{e}$ & $0,0 b$ & $0,0 \mathrm{~b}$ \\
\hline CNT-8 & $64,5 b c d e$ & $19,9 f g h$ & $0,0 f$ & $0,0 \mathrm{e}$ & $0,0 b$ & $0,0 \mathrm{~b}$ \\
\hline Paraguạy-281 & $51,1 \mathrm{de}$ & $12,1 \mathrm{gh}$ & $0,0 f$ & $0,0 \mathrm{e}$ & $0,0 b$ & $0,0 b$ \\
\hline Anahuac & $62,3 \mathrm{bcde}$ & $0,0 h$ & $0,0 f$ & $0,0 e$ & $0,0 b$ & $0,0 b$ \\
\hline D.M.S.(1) & 25,2 & & & & & \\
\hline D.M.S. $\left({ }^{2}\right)$ & 17,5 & & & & & \\
\hline
\end{tabular}

( $\left.{ }^{1}\right)$ Diferença mínima significativa ao nivel de $5 \%$ para a comparação das mécias dos cultivares de trigo dentro de uma mesma concentraçāo de alumínio. Os cultivares seguidos de uma letra comum dentro de uma mesma concentração de aluminio não diferem entre si.

$\left.{ }^{2}\right)$ Diferença mínima significativa ao nível de 5\% para a comparaçāo de cada cultivar de trigo nas concentraçōes de alumínio. 
Os demais cultivares exibiram crescimento das raizes primárias e foram considerados tolerantes a essa concentração de $\mathrm{Al}{ }^{3+}$. $\mathrm{O}$ ' $\mathrm{BH}-1146$ ' exibiu as raizes mais compridas, diferindo dos demais, com exceção dos cultivares IAC-18, IAC-28, IAC-74, IAC-13, IAC-17, PAT-72247, IAC-161 e CEP 7780.

Os cultivares CNT-8, Alondra-S-46 e Paraguay-281 foram totalmente sensiveis a $4 \mathrm{mg} /$ litro de $\mathrm{Al}^{3+}$, isto é, apresentaram paralisação irreversivel no crescimento das raizes após permanecerem 48 horas nas soluções desse tratamento. Nessas condições, 0 ' 'BH-1146' apresentou as raizes mais compridas, diferindo dos demais, com exceção do IAC-18, IAC-28, IAC-74, IAC-13, IAC-17, PAT-72247, IAC-22, Mitacoré, BR-2, IAC-21 e IAC-24.

Os cultivares IAC-162 e IAC-23 foram totalmente sensiveis a $6 \mathrm{mg} / \mathrm{litro}$ de $\mathrm{Al}^{3+}$ e $\mathrm{O}$ ' $\mathrm{BH}-1146$ ' exibiu as raizes mais compridas, somente não diferindo significativamente dos cultivares IAC-18, IAC-28, IAC-24, IAC-74, PAT-72247, IAC-5 e IAC-21.

Os cultivares IAC-17, IAC-161 e CEP-7780 exibiram total sensibilidade ao aluminio a $8 \mathrm{mg} / \mathrm{litro}$ de $\mathrm{Al}^{3+}$. Nessas condiçōes, novamente $\mathrm{O}^{\text {' }} \mathrm{BH}-1146$ ' mostrou o maior crescimento radicular, só não diferindo dos cultivares IAC-28, IAC-18, IAC-24, IAC-21 e PAT-72247.

A $10 \mathrm{mg} /$ litro de $\mathrm{Al}^{3+}$, O 'Mitacoré' exibiu total sensibilidade e somente os cultivares BH-1146, IAC-18, IAC-28, IAC-13, PAT-72247, IAC-21, IAC-24, IAC-74, IAC-22, IAC-5 e BR-2 apresentaram reaçōes de tolerância (Figura 1 e Quadro 2), sendo, portanto, fontes de tolerância à toxicidade de alumínio a utilizar nos programas de melhoramento genético, onde esta característica for desejada.

Seria de grande importância incorporar ao 'Anahuac', pelo método do retrocruzamento, o fator genético de tolerância ao aluminio visando a seu cultivo sem restrição em solos ácidos, uma vez que tem exibido porte baixo e alto potencial produtivo em solos corrigidos, aliado a resistência às raças prevalecentes da ferrugem-do-colmo e da-folha (SĀO PAULLO, 1985, 1986).

Seria interessante utilizar o 'IAC-24', com porte baixo e tolerância a $10 \mathrm{mg} /$ litro de $\mathrm{Al}^{3+}$, nos programas de cruzamentos visando transferir tolerância ao alumínio para os cultivares semi-anões mexicanos, sensiveis a alumínio. Nesse caso, haveria somente segregação para a tolerância ao alumínio nas populações hibridas, e as seleções poderiam ser efetuadas em soluções nutritivas, sem necessidade de avatiação e seleção para o caráter altura das plantas:

\section{CONCLUSÕES}

1) Os cultivares $\mathrm{BH}-1146$, IAC-18, IAC-28, IAC-13, PAT-72247, IAC-21, IAC-24, IAC-74, IAC-22, IAC-5 e BR-2 foram considerados como tolerantes por exibirem crescimento da raiz primária central após tratamento em soluções contendo $10 \mathrm{mg} /$ itro de $\mathrm{Al}^{3+}$. 
2) Os cultivares IAC-17, IAC-161, Mitacoré e CEP 7780 mostraram reação de média tolerância ao $\mathrm{Al}^{3+}$ por apresentarem crescimento da raiz primária central após tratamento em soluções contendo $6 \mathrm{mg} /$ litro de $\mathrm{Al}^{3+}$, porém não apresentando crescimento após tratamento em soluções contendo $10 \mathrm{mg} / \mathrm{litro}$ de $\mathrm{Al}^{3+}$.

3) Os cultivares CNT-8, Alondra-S-46, IAC-162, Paraguay-281 e IAC-23 foram considerados como sensiveis ao $\mathrm{Al}^{3+}$ por exibirem crescimento das raízes primárias após tratamento em soluções contendo $2 \mathrm{mg} /$ litro de $\mathrm{Al}^{3+}$, mas não crescendo após tratamento em soluções com $6 \mathrm{mg} /$ litro de $\mathrm{Al}^{3+}$.

4) $\mathrm{O}$ 'Anahuac' mostrou-se muito sensivel ao $\mathrm{Al}^{3+}$, não exibindo crescimento das raízes primárias após tratamento em soluções contendo $2 \mathrm{mg} / \mathrm{litro}$ de $\mathrm{Al}^{3+}$.

5) Os cultivares Anahuac, Paraguay-281, CNT-8, Alondra-S-46, IAC-162, IAC-23, CEP 7780, Mitacoré, IAC-161 e IAC-17 seriam recomendados para semeadura somente em solos corrigidos sem a presença de $\mathrm{Al}^{3+}$, e BH-1146, IAC-18, IAC-28, IAC-5, IAC-74, IAC-13, PAT-72247, IAC-22, BR-2, IAC-21 e IAC-24, para cultivo em solos ácidos ou corrigidos com a presença de $\mathrm{Al}^{3+}$ abaixo da camada arável.

\section{SUMMARY}

WHEAT: TOLERANCE TO ALUMINUM IN NUTRIENT SOLUTIONS

Twenty one wheat cultivars were studied in aerated nutrient solutions for aluminum tolerance with six different levels, $0,2,4,6,8$ and $10 \mathrm{mg} /$ litro of $\mathrm{Al}^{3+}$, under constant temperature, $25^{\circ} \pm 1^{\circ} \mathrm{C}$ and $\mathrm{pH} 4.0$. Aluminum tolerance was evaluated by measuring the root growth in an aluminum-free complete nutrient solution after a treatment of 48 hours in an aluminum solution. The cultivars BH-1146, IAC-18, IAC-28, IAC-5, IAC-74, IAC-13, PAT-72247, IAC-22, BR-2, IAC-21 and IAC-24 were considered as tolerant because they exhibited growth of the central primary root after a treatment in solutions with $10 \mathrm{mg} / \mathrm{I}$ of $\mathrm{Al}^{3+}$. However cultivars $\mid \mathrm{AC}-17$, IAC-161, Mitacoré and CEP-7780 showed moderate tolerance to $\mathrm{Al}^{3+}$ because they showed growth of the central primary root after a treatment in solutions containing $6 \mathrm{mg} / \mathrm{h}$ of $\mathrm{Al}^{3+}$. Moreover the cultivars CNT-8, Alondra-S-46, IAC-162, Paraguay-281 and IAC-23 were considered as sensitive to $\mathrm{A}^{3+}$ because they did not present root growth after a treatment in solutions with $6 \mathrm{mg} / \mathrm{l}$ of $\left.\mathrm{A}\right|^{3+}$. The cultivar Anahuac did not show any root growth after a treatment in solutions containing $2 \mathrm{mg} / \mathrm{l}$ of $\mathrm{Al}^{3+}$ therefore being considered the most Al sensitive among the studied cultivars.

Index terms: wheat, tolerant and sensitive cultivars, root growth, nutrient solutions, aluminum toxicity. 


\section{REFERÊNCIAS BIBLIOGRÁFICAS}

CAMARGO, C.E.O. Melhoramento do trigo. I. Hereditariedade da tolerância ao alumínio tóxico. Bragantia, Campinas, 40:33-45, 1981.

; CAMARGO, O.B. \& SOUZA, D.M. Diferentes concentraçōes de alumínio em solução nutritiva na tolerância de cultivares de arroz. Bragantia, Campinas, 43(2):357$-368,1984$.

\& FELÍCIO, J.C. Tolerância de cultivares de trigo, triticale e centeio em diferentes niveis de alumínio em solução nutritiva. Bragantia, Campinas, 43(1):9-16, 1984.

\& FREITAS, J.G. Tolerância de cultivares de trigo a diferentes niveis de ferro em solução nutritiva. Bragantia, Campinas, 44(1):65-75, 1985.

\& OLIVEIRA, O.F. Tolerância de cultivares de trigo a diferentes niveis de aluminio em solução nutritiva e no solo. Bragantia, Campinas, 40:21-31, 1981.

LAGOS, M.B.; FERNANDES, M.I.B.M.; CARVALHO, F.I.F. \& CAMARGO, C.E.O. Localização do gene(s) de tolerância ao crestamento em trigo cv. BH-1146 (Triticum aestivum L.). In:REUNIAO NACIONAL DE PESQUISA DE TRIGO, 13., Cruz Aita, 1984. 1p.

MOORE, D.P.; KRONSTAD, W.E. \& METZGER, R.J. Screening wheat for aluminum tolerance. In:WORKSHOP ON PLANT ADAPTATION TO MINERAL STRESS IN PROBLEM SOILS, Beltsville, Maryland, 1976, edited by Madison J. Wright - Proceedings. Ithaca, Cornell University, 1976. p.287-295.

SÃO PAULO. Secretaria da Agricultura e Abastecimento. Relatórios do Acordo entre a S.A.A., através do Instituto Agronômico, e as Cooperativas Rurais do Vale do Paranapanema. Campinas, 1985, 1986. 